\title{
Research on the Meaning of Adding Fujian and Taiwan Traditional Culture into Creative Product Brand
}

\author{
Wei Liu' ${ }^{1, a}$ \\ ${ }^{1}$ Fujian Jiangxia University, Fuzhou, Fujian, China, 350001 \\ aemail,
}

Keywords: Fujian and Taiwan Traditional Culture, Creative Product Brand

\begin{abstract}
With the social development, the value of traditional culture has become increasingly evident and the degree of concern is growing. The studies of traditional culture based on various Fujian and Taiwan are arising in a timely manner. Fujian and Taiwan traditional cultural resources are very rich, the combination of creative products brand new thing "fresh energy" and "profound" traditional culture can meet the needs of current consumption and the development of the times. And it has positive and practical significance to promote Fujian and Taiwan cultural and creative industries with a sound system, promote economic development and promote traditional culture.
\end{abstract}

\section{Introduction}

Today's society has entered a post-industrial era, the widely using of various large-scale, industrialized production of social goods become increasingly saturated. Favor of the pursuit of social production of "flexible accumulation" approach to adapt to rapid change, to promote the traditional "production" gradually dominated the socio-economic transformation to a "consumption" centric model, consumer culture from the traditional "consumer products" to "brand consumption", people add more shopping options on the intangible factors, such as branding, packaging appearance, shape, etc., to meet their shopping emotions in different ways. Innovative products have emerged, not only to meet their practical needs, and more to meet the spiritual needs of consumers, to bring a new consumer experience and fun. Creative market activities have contributed to our innovative product brands and Development.

In the era of brand consumption, one of the industries important "show results" full of life and personality of the brand as a creative cultural and creative industry has aroused great attention, but also for the vigorous development of cultural and creative industry has made tremendous contributions. Creative products brand is the brand of cultural and creative industries vivid performance, it not only as a result of economic development, and more carries spiritual values and cultural connotations. Creative brand of "creative" the most fundamental from the culture, how to create a competitive, with "creative", with "culture" is the key to creative products and creative brand development, but also for the development of cultural and creative industries play a major influences.

The definition of "culture", (1989 new edition) in the definition of "dictionary" of culture is: social ideology, as well as institutions and organizations with suitable. British scientist Taylor on a culture of early classical theory that: Culture is a complex whole including knowledge, belief, art, morals, laws, customs and any person as a member of society and the capabilities and habits acquired, including. It follows that: Culture is the product of human activity created by human activity creating accumulation, human survival and development are generated in the process, recognize and inherited attributes and specific ideology. In today's society, rapid economic development levels and increasingly competitive brand, creative brand of cultural charm lies in competitive given the creative vitality, and culture itself is also full of creativity. Traditional culture of mining is more creative brand development provides a rich and valuable resource, further highlights the advantages.

Traditional culture is a nation after a long history of accumulation form different social environment and customs, which gave birth to have its own unique charm spiritual lifestyle. Not 
only can show the inherent ideology, but also by means of external expansion and extension of the state. In this property, the traditional cultural elements and modern creative elements are closely together, just thoroughly creative products to meet the brand's personality, to achieve the development of cultural and creative industries and historical heritage of unity. Therefore, our provinces should actively explore the development of cultural and creative industries in the extraction of local traditions and cultural resources, developing innovative products, building with distinctive local characteristics of creative brand. Such as "Yunnan" Yunnan is what makes the most of local native culture collide traditional folk dance and art sensory performance of today's cutting-edge occurrence, while retaining most ancient Yunnan local characteristics, while the use of advanced stage art equipment, reproduces rich ethnic Yunnan customs, traditions and achievements of the perfect combination of creative visual feast. "Yunnan" and thus achieved good economic effect, the formation of rich and colorful, and creative products with distinctive features, creating a unique brand of creative products. Fujian and Taiwan traditional cultural heritage, with outstanding geographical characteristics of creative brand Fujian and Taiwan in the development of a rich soil.

Fujian and Taiwan has a long history, contains a fairly strong regional culture. Just across the water between Fujian and Taiwan, Fujian and Taiwan has always been a pro, blood, in the history for a long period of time, Taiwan was part belongs to Fujian. A large number of documents and records show: Fujian and Taiwan residents races and ancient is a branch of the family, the basic necessities of life customary all have similarities. Since the Ming Dynasty after large numbers of immigrants from Fujian to Taiwan, Fujian origin population in Taiwan accounted for about eighty percent of the total population of Taiwan's local political, economic and cultural life had a profound impact on their local residents and Taiwan work together to create a Taiwan local culture. Due to Fujian and Taiwan is similar to the geographical environment, blood blind, the same customs, the same language and it is regarded as a common national culture area. Today, we can clearly see the room framed by geopolitical and blood from the special traditional culture of Fujian and Taiwan, Fujian and we can still feel the same root culture. Folk Belief Culture between Fujian and Taiwan Mazu worship such as, for Guandi pious admiration, so that the interaction between Fujian and Taiwan play a warm effect of friendship; Fujian and Taiwan tea similar resources, Taiwanese kung fu tea Taiwan Kung Fu tea and the same strain, cup of tea carries an important cultural exchange between Fujian and Taiwan regions. Additionally, the South Sound, opera, drama and other high-A folk opera, puppetry, lanterns and other folk arts and crafts are unique characteristics of the traditional culture of Fujian and Taiwan, are to strengthen cross-strait cultural image carrier Love exchanges.

In recent years, the scale of exchanges between Fujian and other political, economic and cultural aspects of the growing areas increasingly extended, cross-strait interaction has entered a fast track of development, exchanges and cooperation in the cultural and creative industries can be seen as more homologous cultural identity, traditional cultural identity of Fujian and Taiwan. Fujian and Taiwan compatriots to promote the traditional culture of Fujian cultural understanding and acceptance, but also for the construction of the West Strait Economic adds a fresh vitality, but also had a strong affinity and cohesion, cross-strait peaceful reunification played a positive interaction effect .

In this context, the value of traditional culture has become increasingly evident, the degree of concern is the growing importance of a timely manner to carry out various studies on traditional culture, Fujian and Taiwan creative brand development should be more rooted in local characteristics, the depth of excavation and extraction of culture element, highlighting the traditional culture of Fujian and Taiwan, highlighting the cultural connotation of creativity.

Fujian and Taiwan has a long history, rich cultural resources, traditional culture should emphasize creative products for the injection characteristics of the brand, the creative products of this brand new thing "fresh vigor" and the traditional culture of "profound" organic integration, improve the brand structure deepen the culture, improve market competitiveness, so that the development of creative product brands have a wider extension of space.

The emergence of creative products to meet the consumer market, while the market demand and 
consumers certainly stimulate more creative products appear, this virtuous cycle, to better promote creative brand development. Brand core idea is "creative", in addition to meeting the practicality of goods, the more is the pursuit of innovation, shine. Smooth and slick to make creative products to please every consumer is difficult, and excessive cater to consumers but will weaken the brand's personality and characteristics, weaken "creative" exists. Consumer creative product itself is the "difference" consumption, if not its own unique brand symbol, creative product brand in terms of lack of creativity. The first is the presence of the brand identity of the brand culture, the role of culture and the close relationship between the brand and brand culture is to enhance the competitiveness of the brand needs. Any kind of creative activity is to be in a certain cultural background. Creative brand contains materiality and culture, it is inevitably influenced by cultural factors, with social and cultural development was gradually increasing trend. So creative products in the process of establishing the brand should pay more attention to their appeal and enrich their cultural connotations. Unique local culture also affects the cultural differences, different geographical and cultural traditions, highlighting the different cultural identities. Fujian and Taiwan creative brand development between Fujian and Taiwan can use just the traditional culture to build creative brand differentiation, increase the brand's unique charm and cultural capital.

In Fujian and Taiwan, the local traditional culture into creative product brands to enhance the awareness of the brand acceptance. Cultural and creative brands included, in particular, it is reasonable into the local traditional culture, help to narrow the psychological distance with consumers, but also to consumer acceptance thereof is even more enhanced.

Fujian and elements of traditional culture from the perspective of cultural values to provide creative brand rich resources, the combination of traditional culture and creative products in Fujian and Taiwan brand, not a simple copy and collage, but through various design forms of traditional culture Get element, refining, into creative expression, relying on its own brand personality, with imagination, creativity and science and technology between Fujian and Taiwan traditional cultural resources for the extraction and sublimation build innovative brands with strong regional characteristics of Fujian and Taiwan. This adds a creative brand culture, rich in creative brand value, creating new opportunities for creative products in Fujian and Taiwan brand survival and development; Meanwhile, Fujian and Taiwan creative product brands Fujian and Taiwan Traditional Culture between a positive and in-depth interaction, to achieve modernization of traditional cultural expressions provide a more dynamic, but also inherit and carry forward the traditional culture of Fujian and Taiwan has made tremendous contributions.

Traditional Culture in Fujian and Taiwan should not just traditional culture of Fujian and Taiwan, should be the traditional culture of the nation and the world composed of content. In today's political environment, rapid economic development, modernization of traditional cultural development in Fujian and Taiwan is particularly prominent. Traditional culture is not "past tense," does not mean static, it should be a dynamic development and the continuation of the process. Fujian and how the traditional culture into the strong creative elements, how to achieve modernization and how to promote international culture is an important issue of creative brand development to face and solve. Fujian and Taiwan traditional culture into creative products brand, is a new way to practice. The communication and development of creative brand are mainly through its branded products and the creation of symbols and behavior to complete. Fujian and Taiwan traditional culture achieve the communication process through the various elements of the brand's creative products. Its brand of modern culture from a development perspective on cultural elements to distill the brand designed to meet the needs of the contemporary aesthetic taste and consumer markets, while focusing on the combination of cultural and creative and practical, to fully absorb the traditional culture of Fujian and Taiwan to promote creative product brands. Fujian and Taiwan to break the inherent traditional culture, learn from existing forms of creative brands such newborn, using a variety of modern advanced media technology creatively transformed their own cultural content, in order to achieve the modernization of traditional culture. Fujian and Taiwan will help expand the modernization of traditional culture through various media channels and in various fields all nations and national dialogue, the status and value of affirmation and recognition of 
traditional culture of Fujian and Taiwan to promote their development through various channels of cooperation or exchange, so Fujian and Taiwan traditional culture to a long history. Inherit and carry forward the traditional culture has now become a trend in consumer demand and cultural development, only to maintain local cultural characteristics, in order to occupy a strong position in the brand competition. The whole society is actually spiritual and cultural entertainment needs-based, high-tech means as a support to the new mode of transmission networks is leading a new round of expansion in Fujian and Taiwan traditional culture, enabling people to pay attention to the traditional culture and pursuit, and then reaches the traditional cultural heritage and carry forward. Taiwan famous writer Pai Hsien-yung led to create a youth version of "Peony Pavilion" is the traditional Chinese opera culture and modern forms of creative products combine excellent performance results. The play not only preserves the cultural essence of traditional opera, but also consistent with the modern aesthetic psychology of the audience, vividly demonstrated a visual feast, succeeded by creative product branding modernization of traditional culture; and youth version of "Peony Pavilion" is also so that gradually fade out of sight of the opera culture to shine again caused concern for the protection of traditional opera culture has made tremendous contribution to the cultural essence of Kunqu heritage and promoting significance.

Fujian and Taiwan creative combination of traditional culture and brand is a lively interactive process. Fujian and Taiwan traditional culture enhance competitiveness of flourish creative brand Fujian and Taiwan cultural and creative industries and. Fujian and Taiwan traditional culture given the strong local brands and creative culture, creative products to extend the brand development, creative brand Fujian and Taiwan also inherit and carry forward the traditional culture show a broader platform. Fujian and Taiwan to Fujian and Taiwan traditional culture into creative products brand, in line with the development needs of today's socio-cultural and creative industries. Only reasonable and effective integration into the traditional culture of Fujian and Taiwan in order to achieve cultural perspective of creative brand development, to meet the needs of the current era of consumption and development of Fujian and Taiwan cultural and creative industries with a sound system, promote economic development, promote the traditional culture positive practical significance.

\section{Acknowledgements}

Fund Project: 2014 Fujian Young Teacher Education Research Project "Creative Brand Research in the Perspective of Fujian and Taiwan Traditional Culture", Item Number: JBS14217.

\section{References}

[1] John Mariotti. Brands and Branding, 2002

[2] Heinz-Joachim Simon. Mystery of Brand, 2003

[3] Yiying Wang. Beijing: Living Reading, 2005

[4] Meina Ma.Wang Kuailiang. Changan University Vol. 29 (2010) No 27, p.21-23

[5] Zhao Yuhua. Dongbei University of Finance and Economics, Vol. 8 (2011) No 27, p.57-60

[6] Zhu Zhaoxuan. Zhejiang University, Vol. 4 (2010) No 27, p. 281-289 